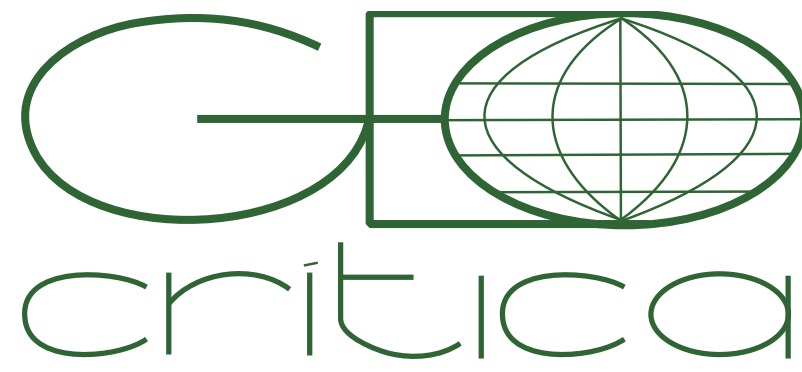

\section{Scripta Nova}

Revista Electrónica de Geografía y Ciencias Sociales Universitat de Barcelona

ISSN: $1138-9788$

Vol. 25, Núm. 3 (2021), p. 165-193

\title{
¿HACIA UNA COMUNIDAD AUTÓNOMA LEONESA? UNA INTERPRETACIÓN URGENTE DEL LEXIT DE INICIOS DE 2020 DESDE LA PERSPECTIVA DE LA NUEVA GEOGRAFÍA REGIONAL
}

\author{
Valerià Paül \\ Universidade de Santiago de Compostela \\ v.paul.carril@usc.gal \\ Roberto Vila-Lage \\ Universidade de Santiago de Compostela \\ roberto.vila.lage@usc.es \\ Alejandro Otero Varela \\ Universidade de Santiago de Compostela \\ alejandrootero.varela@usc.es \\ Juan Manuel Trillo Santamaría \\ Universidade de Santiago de Compostela \\ juanmanuel.trillo@usc.es
}

Recibido: 12 septiembre 2020; Devuelto para correcciones: 15 marzo 2021; Aceptado: 21 abril 2021

¿Hacia una comunidad autónoma leonesa? Una interpretación urgente del Lexit de inicios de $\mathbf{2 0 2 0}$ desde la perspectiva de la Nueva Geografía Regional

(Resumen)

Desde finales de 2019 se ha venido planteando un proceso denominado Lexit, por el que, en base a mociones presentadas en ayuntamientos, se pretende conseguir una comunidad autónoma leonesa separada de la actual Castilla y León. Se interpreta dicho proceso dando voz a sus protagonistas y utilizando el marco teórico de la Nueva Geografía Regional (NGR). Las entrevistas realizadas a tal efecto apuntan a una lectura muy pesimista sobre León y su inserción administrativa, en términos de agravio, ante la que el Lexit emerge como realidad deseada, aunque de difícil consecución. Para este caso particular, resultan más pertinentes las interpretaciones de la NGR que ponen el énfasis en aspectos sociales, económicos y políticos, que las centradas en cuestiones de índole discursiva y cultural.

Palabras clave: Nueva Geografía Regional, región, comunidad autónoma, León, España, Lexit.

Esta contribución ha recibido financiamiento del Ministerio de Universidades a través de las ayudas para la Formación del Profesorado Universitario FPU17/04497 y FPU18/04624.
A Leonese Autonomous Community on a Mutating Political Map of Spain? An Urgent Interpretation of the Early 2020 Lexit Under the New Regional Geography (Abstract) At the end of 2019, the development of a process called Lexit was launched, through which, based on motions presented to local councils, it is hoped to achieve a Leonese autonomous community detached from the current Castile and Leon. This process is interpreted by giving a voice to its main figures and making use of the theoretical frame of the New Regional Geography (NRG). The interviews carried out to that effect indicate a very pessimistic interpretation of Leon and its administrative belonging, in terms of grievance, in which the Lexit emerges as a desired reality, albeit difficult to attain. In this particular case, the interpretations of the NRG placing the emphasis on social, economic and political aspects are more relevant than those centred on discursive and cultural ones.

Key words: New Regional Geography, region, autonomous community, Leon, Spain, Lexit. 
El 28 de diciembre de 2019 la prensa de alcance español dedicó grandes titulares a la aprobación de una moción por parte del Ayuntamiento de León para separar la Región Leonesa ${ }^{1}$ del resto de su actual comunidad autónoma (figura 1). No fueron pocos los que creyeron que se trataba de la tradicional inocentada con la que cada año suelen bromear los medios en esa señalada fecha navideña. No obstante, esta interpretación superficial oculta el arraigo en la ciudad y en la provincia homónimas de un parecer favorable a una autonomía aparte de Castilla. Con considerable rapidez, la moción se ha ido extendiendo por otros municipios, sobre todo pertenecientes a la provincia de León. Este proceso se ha venido a denominar Lexit (figura 2), una feliz expresión que retomamos aquí, emulando de forma perspicaz el famoso Brexit del Reino Unido culminado precisamente en enero de 2020.

Las preguntas en torno al recorrido que estas mociones pueden alcanzar se han ido sucediendo en las plataformas mediáticas; sin embargo, se antoja necesaria una investigación interpretativa que analice lo que está ocurriendo a la luz de los postulados de un corpus teórico que nos parece pertinente para ello, como es el de la Nueva Geografía Regional (NGR), una suerte de interfaz, generada a partir de la década de 1970, entre la Geografía Regional, la Geografía Cultural y la Geopolítica. Perseguimos además elucidar el porqué de este planteamiento contemporáneo y determinar de qué forma (re)elabora visiones precedentes que apuntaban en una dirección similar. A su vez, y relacionado con lo anterior, resulta de interés escudriñar las razones de la velocidad de propagación del discurso, así como aventurar su sostenibilidad en el tiempo, habida cuenta de que se le ha tildado repetidamente de adventicio.

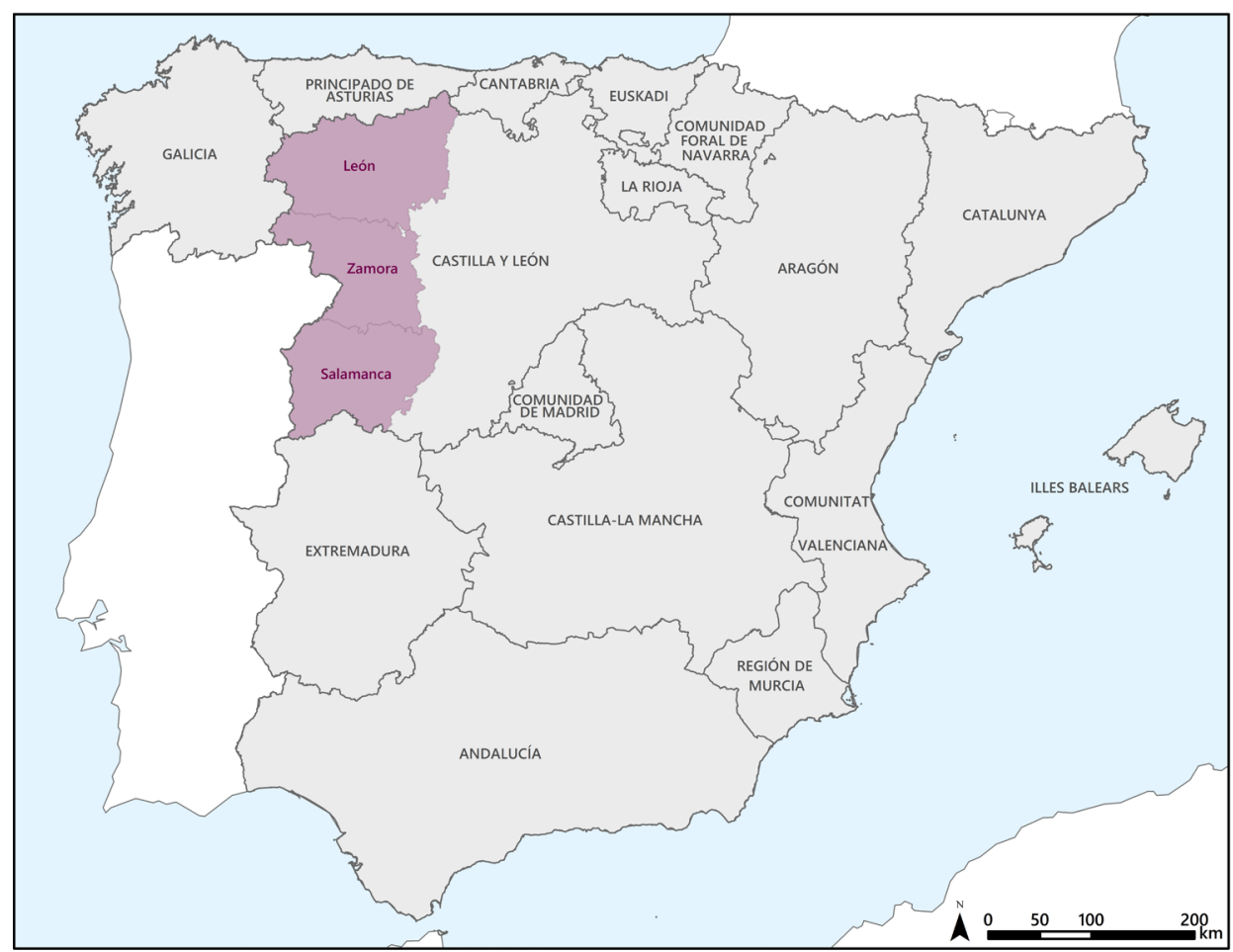

Figura 1. La Región Leonesa en el mapa autonómico actual.

Fuente: Elaboración propia.

1 Entenderemos por Región Leonesa la suma de las actuales provincias de León, Salamanca y Zamora, según el mapa implantado en 1833 y aún vigente. El segundo apartado de este texto ahonda en esta cuestión. 


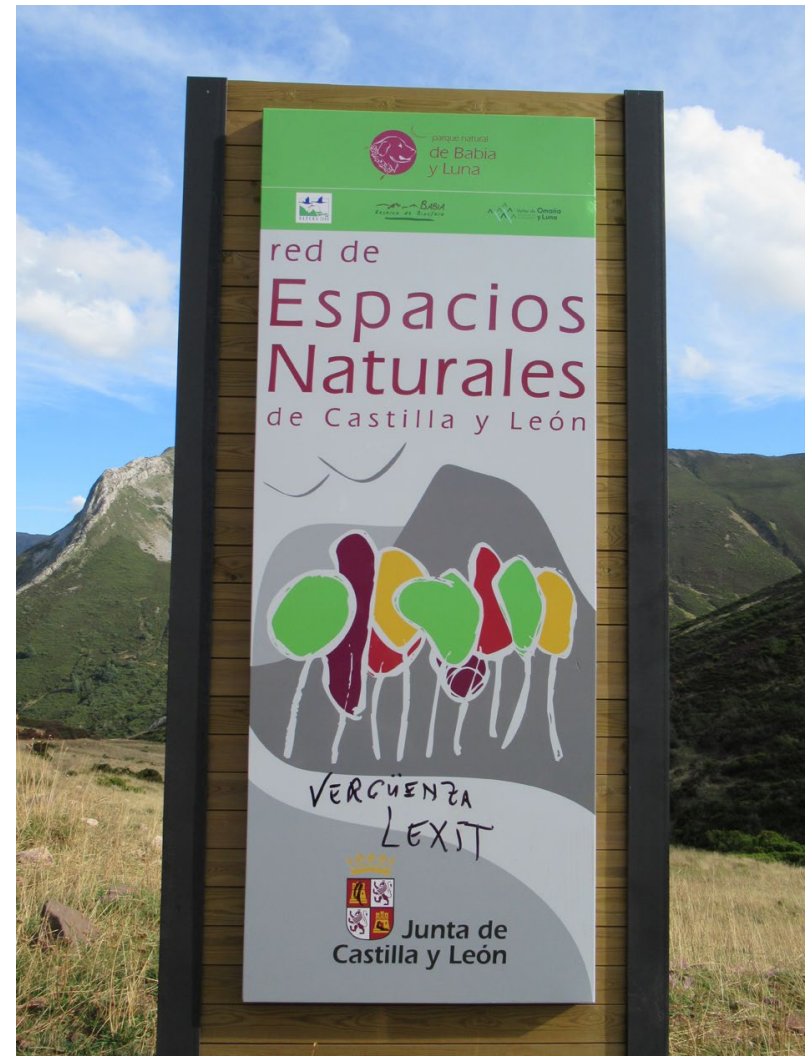

Figura 2. Pintada reivindicativa favorable al Lexit en la entrada desde Asturias al Parque Natural de Babia y Luna, perteneciente a la Red de Espacios Naturales Protegidos de Castilla y León.

Fuente: Fotografía propia (26/8/2020).

Para la consecución de estos objetivos, optamos por realizar entrevistas semiestructuradas, que permiten dar voz a los actores vinculados al proceso. Este método ha posibilitado construir los apartados empíricos de esta contribución. En un debate reiterado hasta la saciedad, se ha tendido a atribuir un carácter exclusivamente inductivo a las técnicas cualitativas (Taylor y Bogdan 1984). Sin embargo, dudamos de este encasillamiento, de modo que los planteamientos teóricos de partida constituyen un marco interpretativo que aporta una pátina deductiva. Así pues, el próximo apartado contiene las claves acerca del concepto región en las coordenadas teóricas mencionadas, a las que le sigue una contextualización geohistórica de la Región Leonesa. Después de las consideraciones metodológicas, el apartado de resultados ofrece los análisis realizados. La discusión hilvana los materiales del epígrafe anterior con el marco teórico previamente aportado, de modo que testea la capacidad de este segundo para comprender el Lexit. Un último apartado, a modo de epílogo, presenta la situación actual del proceso estudiado (abril de 2021), habida cuenta del tiempo transcurrido desde la realización del trabajo de campo (febrero de 2020).

No se persigue, en fin, desarrollar un mero «estudio de caso» — sin negar lo que tiene de ello-; se procura también aportar una aplicación contemporánea en torno al concepto región a la luz de la NGR. En este sentido, el presente trabajo puede ser de utilidad para interpretar una de las tantas pulsiones territoriales experimentadas en la España de la segunda década del siglo XXI, período que se ha caracterizado por una eclosión de conflictos 
territoriales que se consideraban superados desde la pretendida pax hispanica instalada con la Constitución de 1978 (Gómez Mendoza et al. 2013; Farinós et al. 2019). A la vez, pretendemos favorecer la reflexión teórico-conceptual sobre el concepto región mediante unos prismas que desbordan los planteamientos de la Geografía Regional clásica.

\section{La región como construcción socio-espacial}

Intentar ofrecer una definición de un término tan fundamental para la Geografía como región implica adentrarse en veredas tortuosas plagadas de encrucijadas. Como acertadamente indican Farinós y Fernández Enríquez $(2017,19)$, «uno de los retos principales a los que ha debido enfrentarse nuestra disciplina ha sido la ausencia de una definición comúnmente aceptada de lo que entender por región». Para Agnew $(2018,24)$, resulta «tan lábil y resbaladiza» ${ }^{2}$ a causa de la dificultad de precisar sus fronteras. Ello, a pesar de -o tal vez en parte debido a - ser un vocablo que usamos sin problemas en nuestra vida diaria, como indica Cochrane (2018). En efecto, se trata de un término, como otros de contenido espacial, que se ha convertido en «tótem para los campos académicos y otras esferas de la práctica profesional y política» (Paasi y Metzger 2017, 21). En este sentido, en una reciente revisión coral del tema regional, los editores de la obra afirman sin tapujos que «entender las regiones y el regionalismo en contexto es uno, si no el más importante, de los retos a los que se enfrentan los académicos en la actualidad» (Paasi et al. 2018, 12).

Al hilo de estas opiniones acerca del hecho regional, cabe situar el foco en discernir «qué imaginarios espaciales es probable que sean de corta duración y que acaben por desaparecer, cuáles se están convirtiendo en formas institucionalizadas consolidadas y cuáles permanecerán como "blandos" en el tiempo» (Paasi et al. 2018, 17). Estos imaginarios pueden construirse, según Agnew (2018), en torno a distintas maneras de enfocar lo regional, entre las que se encuentran las denominadas «regiones subnacionales» ${ }^{3}$. Sobre estas últimas, afirma que «ha habido un incremento masivo de demandas políticas por parte de la población de ciertas regiones, sobre todo periféricas, buscando tener una mayor voz sobre su futuro político y económico» (Agnew 2018, 28).

Dichas «regiones subnacionales» pueden ponerse en paralelo, por lo menos, con tres de las opciones regionalistas que distingue Keating $(2017,11)$ al explorar «las diversas maneras de construir la región como un proyecto económico, social y político»: el regionalismo identitario, el gubernamental y el que refleja los intereses sociales y económicos. Así, se defiende un marco particular para una cultura diferenciada, lo que puede conducir a reivindicar un gobierno propio que se concibe como instrumento para alcanzar las cotas políticas, sociales y económicas del grupo.

2 Traducción propia, de esta y del resto de citas distintas del español.

3 Subnacional es una traducción literal del inglés, que en castellano se podría expresar como subestatal. En este supuesto, cabría entender Estado en el sentido de administración central de un territorio reconocido internacionalmente como independiente, no aquellos estados federados en el caso de regímenes políticos más o menos federales. 
Jones y Paasi (2015) y Paasi et al. (2018) han identificado cinco "geografías cambiantes de las regiones y territorios», de las que nos interesa especialmente la NGR surgida a partir de los años 1970. Esta incide en la dimensión construida de la región (García Álvarez 2006), que ha pasado a definirse como una construcción social en el espacio, fruto de la interacción de agentes en un contexto específico. La clave de la investigación radica en cuestionarse quién y cómo se construye la región, para lo que es necesario tener en cuenta una plétora de «actores como políticos, empresarios, periodistas, profesores y asociaciones profesionales [que] se conciben como portadores clave de posiciones en tanto que activistas o promotores en el proceso de articular los significados y las funciones vinculadas a las regiones» (Paasi y Metzger 2017, 22). La novedad epistemológica -pero también ontológica- estriba en que el investigador no es un ente externo que busca construir o descubrir una región concreta - como podría hacer la Geografía vidaliana-, sino que ha de estar atento para «aprehender[la] como el resultado de procesos cambiantes de construcción regional o regionalización» (Paasi y Metzger 2017, 22). Es fundamental, en este sentido, reconocer «el papel de las organizaciones de la sociedad civil y los movimientos locales en la conformación de los regionalismos» (Paasi et al. 2018, 12).

Dentro de la NGR destaca el modelo de construcción regional de Paasi (1986), que ha sido aplicado tanto en una escala infraestatal, ya sea en Estados federados -Paül y Haslam Mckenzie (2015) para Australia Occidental—, casi/semi-federales —García Álvarez (2002) para las comunidades autónomas españolas- o naciones sin Estado -MacLeod (1998) para Escocia-, como en procesos más recientes de institucionalización de regiones transfronterizas (Trillo 2014). La propuesta de Paasi aporta un marco de análisis para entender cómo se producen y reproducen los procesos socio-espaciales que conforman una región. En lo sustancial, ha mantenido invariable el modelo de 1986 en las décadas siguientes (por ejemplo, en publicaciones de 1991, 1996, 2001 y 2004). Para este autor, lo regional pasa indefectiblemente por su institucionalización, esto es, «un proceso socio-espacial en el que una unidad territorial emerge como parte de una estructura espacial de la sociedad concernida, llega a establecerse e identificarse en varias esferas de la acción y conciencia sociales, y puede eventualmente desaparecer o des-institucionalizarse» (Paasi 1991, 243). Distingue cuatro fases para poder alcanzar su consecución, que no tienen por qué darse de manera cronológica, ni siquiera han de desarrollarse todas:

1. Asunción de la forma y conciencia territoriales. Se ha de contar con una delimitación que diferencie una región de otras. Se necesita establecer fronteras, definidas como «instituciones y símbolos que están sedimentados en numerosas prácticas territoriales» (Paasi 2001, 22). El espacio comienza así a ser dotado de significado, de manera que la base material de la región —en tanto unidad territorial (su medio físico, su emplazamiento, etc.) —, será el marco para poder elaborar representaciones, paisajes o discursos (Paasi 1991). En el caso de alcanzar una forma unificada, podría llegarse a contar con un mapa para el territorio, que podría ser definido, en términos de Anderson (1986), como un «logotipo». 
2. Construcción de la forma simbólico-conceptual. El mapa tiene que ser llenado de contenido, con el fin de que se convierta en marco de referencia. Elemento esencial será el corónimo, que suele ir de la mano de la elaboración de una narración histórica que lo justifique, dentro de una continuidad temporal que se proyecta hacia el pasado. Se acompañará este quehacer de rituales, canciones, novelas, libros... en los que su protagonista sea la nueva unidad regional.

3. Desarrollo de la esfera de las instituciones, tanto formales como informales, que median la producción y reproducción de la región. Así, se consideran instituciones los sistemas y programas educativos (en especial los históricos y geográficos), la prensa, las empresas, compañías, entidades administrativas, asociaciones y otros organismos de la sociedad civil, etc.

4. La región como parte establecida tanto del sistema regional como de la conciencia regional de los habitantes. Esta fase implica que la región ha alcanzado su integración en la estructura espacial de la sociedad y en la conciencia social, de manera que se presenta como marco de acción con capacidad suficiente para entablar luchas ideológicas, de recursos, de poder, etc. que la pueden llevar a contraponerse con otras regiones. Sin duda, la posibilidad de erigirse en un ente político-administrativo reforzará la posición de esta, aunque Paasi incide en que lo fundamental son las instituciones que reproducen la conciencia social y la imprimen en las prácticas diarias de los habitantes: medios de comunicación, sistema educativo, etc.

Otro modelo que bebe, en buena medida, de la NGR es el de Lagendijk (2007). Este autor, además, aúna en su propuesta argumentos provenientes de lo que Jessop (2001) ha denominado enfoques «estratégico-relacionales» que ayuden a estudiar la producción y reproducción de instituciones en un contexto socio-espacial determinado. De este modo, Lagendijk, según MacLeod (2001), integra en el análisis regional dos tipos de elementos: por un lado, los denominados «blandos», esto es, centrados en la agencia y capacidad de los distintos actores de moldear discursiva y materialmente la región, que serían los más coherentes con Paasi; por otro lado, los llamados «duros», relativos a las condiciones sociales, económicas y políticas de un tiempo y lugar concretos, que constriñen las posibilidades de acción, y que no estarían bien especificados en el modelo de Paasi, y sí en propuestas como la de Jessop et al. (2008).

A su vez, Lagendijk (2007) también incorpora el interés por el análisis del discurso, esto es, las distintas narrativas que pueden elaborar los actores en los denominados «contextos de selección estratégica». Las ideas que mejor se adapten a esa situación conformarán las bases del «imaginario hegemónico». La producción de hegemonías es la clave para entender el modelo de Lagendijk: aquellos grupos sociales que mejor respondan con sus estrategias a las condiciones estructurales en las que se ven insertos impondrán sus proyectos e imaginarios regionales. Estos podrán ser puestos en cuestión por varios motivos, dando así lugar a modificaciones e, incluso, sustituciones de imaginarios. Sum (2004) ha 
distinguido cinco momentos claves para entender este proceso, propuesta sobre la que se apoya Lagendijk (2007) para postular la suya:

1. Se abren ventanas de oportunidad o de cambio, que pueden tener un doble origen. Uno posible es la percepción de transformaciones externas o internas respecto de un proceso particular dado.

2. Otra ventana de cambio consiste en la modificación de los discursos, aunque no haya mediado un cambio en las condiciones estructurales y/o las relaciones sociales.

3. Momento (inter)discursivo-selectivo: una vez que se abren las ventanas de oportunidad, viejos o nuevos actores reaccionan a los cambios y proponen nuevos discursos, nuevas narrativas, nuevos estándares y pautas de acción.

4. Reconfiguración de actores, subjetividades y formación de nuevos imaginarios hegemónicos.

5. Estas prácticas discursivas pasan a ser regularizadas e institucionalizadas en nuevas formas de gobernanza, de modo que se otorga una nueva coherencia estructural, además de interiorizarse nuevas relaciones de poder, privilegios sociales, etc.

Lagendijk (2007) indica que su propuesta complementa otras de la teoría regional contemporánea que se han orientado sobre todo hacia las fases 4 y 5 , y pone el modelo de Paasi (1986) como ejemplo. Así, el momento 4 correspondería a la formación territorial y simbólica de Paasi (1986); y el 5, al desarrollo de las instituciones y a la reproducción de la región como parte del sistema y la conciencia regionales. De esta manera, las fases 1 a 3 ofrecen una mayor dimensión temporal en el análisis de la formación regional. Por último, cabe completar esta propuesta con una aportación coautorizada por el mismo autor respecto de tres tipos de identidad, que se antoja relevante para el momento 4:

- estratégica: identificación de un territorio que sea base para la acción común;

- cultural: dotación de un contenido simbólico y elaboración de una idea de un «nosotros» frente a un «otros», así como posicionamiento de la región en el mapa; y

- funcional: consolidación de proyectos comunes que se desarrollarán en la región (Houtum y Lagendijk 2001).

\section{La Región Leonesa}

Determinar desde cuándo existe una unidad territorial leonesa constituye una tarea ardua que nos retrotrae al menos dos milenios, aunque este artículo prime una visión actual. No obstante, resulta relevante referirse a los antecedentes. La primera demarcación reconocible de la Península Ibérica se debe a la dominación romana, que individualizó en el noroeste peninsular una provincia, la GALLAECIA, en la que se incluirían lato sensu no solo las actuales tres provincias que aquí consideramos la Región Leonesa, sino también otros territorios (el 
Norte de Portugal y Asturias) y la actual Galicia, que ha heredado su nombre. No obstante, se desconoce el detalle de sus límites externos e internos, que han sido objeto de controversias, si es que estos estaban dotados de tanta precisión como con la que se opera hoy en día. El asunto de los límites internos resulta relevante, dado que buena parte de la Región Leonesa, más la actual Asturias, se corresponderían con el convento asturicense (uno de los tres en los que se dividía la GALLAECIA), que sería el referente territorial original de ambas; en efecto, la especificidad de los astures era marcada en frente a los galaicos estrictos de los dos conventos atlánticos de la GallaEcia (De Hoz 2010; Santos 2010). La capital conventual, AsturiCA AUgUSTA, actualmente Astorga, pertenece en la actualidad a la provincia de León. En las proximidades de dicha ciudad surgió, con el asentamiento de una legión, el núcleo de LEGIO (hoy, León). Con el paso de los siglos esa denominación ha dado lugar a un corónimo.

La identidad histórica de este territorio conventual se demuestra con la pervivencia a lo largo de los siglos de una evolución patrimonial del latín distinto del castellano: el asturleonés (también denominado asturiano o leonés). Solo subsiste en Asturias (con un cierto reconocimiento legal), en Miranda do Douro (Portugal, donde está amparado legalmente desde 1999) y, a duras penas, en algunas comarcas occidentales de las actuales provincias de León y Zamora (Fernández Rei 2007; Salgado 2016).

La desaparición del dominio romano en la GALLAECIA a principios del siglo $\mathrm{V}$ a manos de los suevos y, sobre todo, la consolidación del control musulmán en la mayor parte de la Península Ibérica tres siglos después implican hondas transformaciones territoriales. La interpretación prevaleciente apunta a que las autoridades cristianas que quedan fuera del control musulmán en el ámbito de la GALLAECIA se articulan en el propio siglo viII alrededor del Reino de Asturias, que, al desplazarse la corte de Oviedo a la ciudad de León a principios del siglo x según se acostumbra a convenir, deviene Reino de León (cfr. García Álvarez 2002, 123-124). Su ámbito, aunque fusionado -incorporado de facto - con Castilla en el siglo XIII, constituirá una unidad territorial insoslayable (Salgado 2016; Ferrer 2017). Así, en el propio siglo XIII aún se distinguía comúnmente entre las Cortes de León y las de Castilla, aunque las reuniones fueran conjuntas, pero en los siglos posteriores pasaron a denominarse de Castilla. De todos modos, cabe mencionar que esta tesis generalizada ha sido rebatida en los últimos años, al menos desde Nogueira (2001). En lo fundamental, esta otra perspectiva, desarrollada in extenso por López Carreira (2005) o Andrade y López Carreira (2020), defiende que el Reino de León no existió como tal en los siglos IX-X, sino que formaba parte del Reino de Galicia, heredero de la GALLAECiA. Así, la diferenciación entre el territorio leonés y la Galicia estricta no se produciría hasta avanzada la edad media, a la vez que el destino de León se unía progresivamente al de Castilla.

Hasta el establecimiento del Estado liberal en el siglo xIX no se definen con precisión y cartografían los límites territoriales, y el caso leonés no constituye una excepción. Resulta revelador observar cómo en la colección de mapas más famosa del siglo XVII, de la fábrica de Blaeu, hallamos dos versiones de la Regnorum Hispaniae nova descriptio. En la de 1640, se utiliza una misma iluminación para Castilla y León, aunque se rotula León en letras de igual tamaño que Castilla. En cambio, la de 1643 delimita León, incluyendo un territorio mucho más amplio que la Región Leonesa actual y, de hecho, excluyendo dos de sus provincias 
-Zamora, en parte, y Salamanca, en su totalidad-. ${ }^{4}$ Obviamente, en tres años no se crea un reino (si tomamos la literalidad del título del mapa), sino que el paradigma cartográficoterritorial estaba en ciernes. Y no se puede olvidar que «los territorios generan y requieren mapas para su afirmación y definición política, y es igualmente cierto lo inverso: la existencia de mapas de determinado ámbito geográfico propone y refuerza identidades» (Burgueño 2011, 23).

En todo caso, el entendimiento de León como una región está plenamente asentado en el setecientos: en el mapa España dividida según acostumbran los geógrafos de Tomás López (1757) aparece configurada como tal, aunque sumando, a las que se consideran normalmente las tres provincias leonesas, bastante territorio hacia el este, como ya había hecho la escuela de Blaeu. De hecho, un Diccionario geográfico notable de mediados del siglo XIX, el de Madoz (1847, X, 132), considera que el Reino de León «en su último estado correspondía aproximadamente al que hoy ocupan las 5 prov. de León, Palencia, Valladolid, Zamora y Salamanca».

Más allá de los usos y costumbres de cartógrafos y geógrafos, desde una perspectiva administrativa, todo aquel territorio regido por una ciudad con voto en Cortes en la Corona de Castilla bajomedieval y moderna se fue denominando provincia, inicialmente solo a efectos fiscales (Burgueño 1996 y 2011; García Álvarez 2002). Si tenemos en cuenta las tres provincias consideradas leonesas actualmente, en el siglo XVI estas ya existen, con límites distintos y a veces incorporando un territorio mayor: Salamanca hacia el sur (con Extremadura); León hacia el norte (con Asturias); Zamora; y una cuarta, que desaparecerá, de Toro. Además, se hallan enclaves de otras provincias, sobre todo de Valladolid.

Por otro lado, no cabe realizar una presentación del territorio leonés como se ha dado en entender contemporáneamente sin referirse a la especificidad del Bierzo. No hay duda de su adscripción en época romana a la GALLAECIA y, dentro de ella, al mundo asturicense. Desde la alta edad media, se individualiza claramente como territorio (Rodríguez González y Durany 1997), denominado en ocasiones provincia, dentro del uso errático, o cuanto menos ambiguo, de esta palabra en la edad moderna (Burgueño 1996 y 2011; García Álvarez 2002). De hecho, el mapa de Tomás López de 1786 se denomina del Partido de Ponferrada, que suelen llamar regularmente Provincia del Vierzo ${ }^{5}$. En la única división aprobada por las Cortes, la de 1822, el Bierzo es provincia, con capital en Villafranca — su precedente más directo, la propuesta de Bauzà y Larramendi de 1821, la colocaba en Ponferrada- (Burgueño 1996 y 2011; García Álvarez 2002). Sin embargo, dicho estatus provincial se pierde pasado el Trienio Liberal, aunque la individualidad berciana ha permanecido a lo largo de los siglos y, de hecho, en el actual período autonómico, se trata de la única comarca de la actual comunidad de Castilla y León dotada de órganos de gobierno comarcal (Ley 1/1991, de 14 de marzo, por la que se crea y regula la Comarca de El Bierzo).

La planta provincial que se ha venido revisando permanece a grandes rasgos hasta el siglo XVIII (Burgueño 2011). En 1833 se aprueba la división provincial de España que aún hoy

4 Ambos mapas se encuentran en https://cartotecadigital.icgc.cat/digital/ (Consulta 7/9/2020).

5 https://bibliotecadigital.jcyl.es/es/consulta/registro.cmd?id=11827 (Consulta 19/4/2021). 
sigue vigente. Aunque se haya magnificado la contribución de Javier de Burgos, el ministro en el cargo en el momento de su aprobación, ha pasado a la posteridad con su autoría (Burgueño 1996 y 2011). En el decreto, las provincias son enumeradas por territorios, en el caso que nos ocupa: «El reino de León [se divide] en las [provincias] de León, Salamanca y Zamora». ${ }^{6}$ De aquí la referencia continúa en este texto a las «tres provincias leonesas». Irónicamente, el «Reino de León» se delimita con precisión cuando el Estado español busca su propia consolidación y pretende aniquilar su diversidad constitutiva.

A partir de 1833, se consolida la división de España en estas provincias; sin embargo, la organización regional en el sentido político español ha resultado en un conflicto prolongado (García Álvarez 2002) que, en sus ramificaciones, llega hasta nuestra contemporaneidad. Así, en nuestro caso de estudio, los territorios provinciales se han asentado, gobernados cada uno de ellos por una diputación provincial con capacidad de implantación sostenida durante más de siglo y medio, cuya delimitación es utilizada por la administración del Estado en sus distintas expresiones. En cambio, el «Reino de León» de la división de 1833 no se ha reconocido como tal. De todos modos, durante siglo y medio se estudió en el ámbito escolar, lo que garantizó su difusión hasta la década de 1980 (García Álvarez 2002; Salgado 2016).

De acuerdo con Salgado (2016) y Ferrer (2017), el regionalismo leonés que reivindica estas tres provincias como una región diferenciada merecedora de autonomía aparece a finales de la década de 1970 y, sobre todo, en la de 1980, aunque exista algún antecedente en las primeras décadas del siglo Xx. Así pues, el leonesismo se puede vincular con la conformación del mapa político de España surgido de la Constitución de 1978. Cabe tener en cuenta que, al menos desde 1975 y con antecedentes a inicios del siglo xx, existían instancias que defendían la constitución de una región de «Castilla y León», es decir, englobando ocho provincias más que las tres leonesas (García Álvarez 2002; Salgado 2016). De todos modos, la actual Castilla y León echó a andar en una reunión de sus responsables políticos en 1978 ya sin dos de esas provincias - las futuras comunidades de La Rioja y Cantabria, que se desgajan de aquella propuesta inicial tras las primeras elecciones de 1977-. A dicha reunión no acudieron los representantes de León, aunque sí los de Zamora y Salamanca, seguramente a causa de la manifestación de cientos de miles de personas bajo el lema «Por la autonomía y el referéndum de la Región Leonesa. León sin Castilla» del 18 de marzo de 1978.

De acuerdo con García Álvarez (2002), la reivindicación de la Región Leonesa en aquellos años 1970-1980 se concentra en el ámbito de la provincia de León y recoge pocas adhesiones en Zamora y, aún menos, en Salamanca. A la postre, la entrada de León en Castilla y León se fuerza en 1980 por «razón de Estado», como «barrera de contención» a los nacionalismos vasco y catalán (García Álvarez 2002, 519-530). La idea, pocas veces verbalizada, consiste en que una Castilla y León fuerte — se trata de la región autónoma más grande de España y con más provincias- actuaría a nivel nacional como contrapeso o tapón frente a dichos nacionalismos.

6 Art. 2, «Real decreto [sobre] la divisi[ó]n civil del territorio [...] español en la Península [e] islas adyacentes [...] en 49 provincias», Gaceta de Madrid, 3/12/1833 (no 154): 657-658. Disponible en: https://www.boe.es/datos/pdfs/BOE//1833/154/A00657-00658.pdf (Consulta 20/7/2016). 
El leonesismo persigue desde inicios de la década de 1980 el establecimiento de una comunidad autónoma para León, con las tres provincias (Ferrer 2017). Su punto álgido pudo ser la manifestación de 1984, con miles de personas bajo la pancarta «León solo», motivada por el proceso ante el Tribunal Constitucional para intentar revocar la unión con Castilla, de resultado infructuoso (Salgado 2016). De acuerdo con García Álvarez $(2002,696)$, el leonesismo «h[a] experimentado un significativo crecimiento durante los últimos años en su provincia [...] [aunque] sigu[e] en clara minoría». De este modo, no parece haber conseguido llegar a ser dominante y se ciñe a la provincia de León. Ferrer $(2017,82-86)$ indica que el regionalismo leonés sufre una crisis a causa de su división entre 2003 y 2015; desde 2015, detecta una reactivación de estas demandas. En este contexto, la presente investigación se refiere a lo acontecido en el tránsito entre 2019 y 2020.

En último lugar, y para calibrar el respaldo popular que las reivindicaciones leonesistas puedan tener, cabe reseñar que en 2020 se realizó por parte de Electomanía una encuesta de la que se ofrecieron dos explotaciones: una sobre el conjunto de Castilla y León ${ }^{7}$ y otra sobre el Bierzo en particular ${ }^{8}$. En la primera, se infiere que el apoyo a una autonomía leonesa triprovincial es mayoritario en la provincia de León (46\%) y concita un apoyo de menos de un tercio de la población en Zamora y Salamanca (27\% en ambas), en las que, por el contrario, mantener el status quo es la opción preponderante (30 y 28\%, respectivamente). En las tres, ronda el 10\% la opción de una autonomía uniprovincial de León. Otras opciones con cierta extensión, alrededor también del 10\%, son, en Salamanca y Zamora, ampliar con más provincias la actual comunidad autónoma; en León, a su vez, lo es mantener el status quo, pero con el matiz de «reordenar territorios como el Bierzo». Sobre el Bierzo concretamente, y haciéndonos eco solo del muestreo en la comarca, la primera opción es la unión con Galicia como provincia diferenciada, casi empatada con la segunda: el mantenimiento en Castilla y León, pero también como provincia propia (respectivamente, 26,2 y $25,5 \%$ ). La tercera opción, la constitución de una comunidad autónoma leonesa, les sigue de cerca $(23,7 \%)$. El 14,1\% de los bercianos están a favor del mantenimiento del status quo y el resto de las opciones planteadas son minoritarias.

\section{Consideraciones metodológicas}

Para la realización de esta investigación se efectuaron entrevistas semiestructuradas aplicando las indicaciones metodológicas de Taylor y Bogdan (1984), Ruiz Olabuénaga (1999), Valentine (2005), Seidman (2006) y Kvale (2011). El uso de este tipo de técnicas cualitativas no busca la representatividad — propia de las técnicas cuantitativas-, sino que persigue que las personas entrevistadas construyan «sus propios relatos a partir de sus experiencias describiendo y explicando sus vidas con sus propias palabras», esto es, que la investigación consiga «entender cómo las personas experimentan y conceden sentido a sus

7 https://electomania.es/electopanel-1j-ii-castilla-y-leon-dividida-por-la-region-leonesa/

(Consulta 19/4/2021).

8 https://electomania.es/electopanel-23my-la-comarca-del-bierzo-apuesta-por-constituirse-como-provincia/ (Consulta 19/4/2021). 
propias vidas» (Valentine 2005, 111). En definitiva, comprender cómo perciben las protagonistas el proceso del Lexit y los argumentos que activan en su reivindicación.

Las entrevistas se realizaron durante la primera mitad de febrero de 2020, antes del confinamiento iniciado en marzo debido a la pandemia de la Covid-19, empleando un único modelo de entrevista. Dicho prototipo se estructuraba en cinco grandes bloques:

- perfil de la persona entrevistada, que pretende hacer emerger las coordenadas básicas de los entrevistados y establecer un vínculo de confianza;

- percepción territorial, con el objetivo de explorar los cambios percibidos en el territorio, así como los discursos asociados a los mismos;

- identidad, en el que se abordan cuestiones relacionadas con el sentimiento de pertenencia;

- visión acerca de la organización territorial, donde se trata todo lo concerniente al marco territorial vigente y a las administraciones públicas con presencia en el territorio;

- y percepción del proceso por la autonomía leonesa, buscando conocer cómo entienden el Lexit y su desarrollo.

Debido a la flexibilidad de las entrevistas semiestructuradas (Ruiz Olabuénaga 1999; Lune y Berg 2017) y a las características particulares de cada persona entrevistada, el orden de dichos apartados y la profundización en cada uno de ellos resultaba variable. Siguiendo lo propuesto por Taylor y Bogdan (1984), Ruiz Olabuénaga (1999), Kvale (2011) o Maxwell (2013), en aras de dotar a las entrevistadas de libertad para responder, cada uno de los bloques se componía de una serie de preguntas abiertas. En la medida de lo posible, el entrevistador no mencionaba palabras como «comunidad autónoma», «región» o «Lexit», esperando que el interlocutor les concediera sentido en su relato sin necesidad de introducirlas previamente (Cameron 2016).

Se entrevistó a 16 personas, dialogando de media una hora con cada una de ellas. 12 de las entrevistadas eran políticas en activo con participación directa en la elaboración y aprobación de las mociones en 11 municipios diferentes; estas fueron contactadas tras conocer por la prensa los resultados en cada corporación. Cabe subrayar, como ya se ha dicho más arriba, que «[1]a tarea de seleccionar muestras representativas [...] ocup[a] un segundo lugar en la metodología cualitativa», siendo un «trabajo de menor importancia en la mayoría de las ocasiones» (Ruiz Olabuénaga 1999, 63). En este punto, se busca «escoger quién entrevistar [...] [en base a] una decisión motivada teóricamente» (Valentine 2005, 112), lo que Ruiz Olabuénaga $(1999,64)$ denomina «muestreo intencional». En todo caso, y sin entrar en una justificación cuantitativa que no ha lugar en este marco epistemológico, cabe tener en cuenta que a inicios de febrero de 2020 el número de ayuntamientos con moción aprobada era de 20 y que sumaban, en conjunto, un total de 159.927 habitantes; 18 de los 20 pertenecían a la provincia de León, de modo que se había alcanzado entonces el 35\% de su población (figura 3). Las otras 4 entrevistas se consiguieron a través de la técnica de «bola de nieve» (Ruiz Olabuénaga 1999, 64; Valentine 2005, 117) y las redes sociales, de modo que 
se pudo dialogar con 3 personas militantes del leonesismo más reivindicativo y con 1 político en activo cuyo municipio, a febrero de 2020, aún no había discutido la moción, pero autonomista.

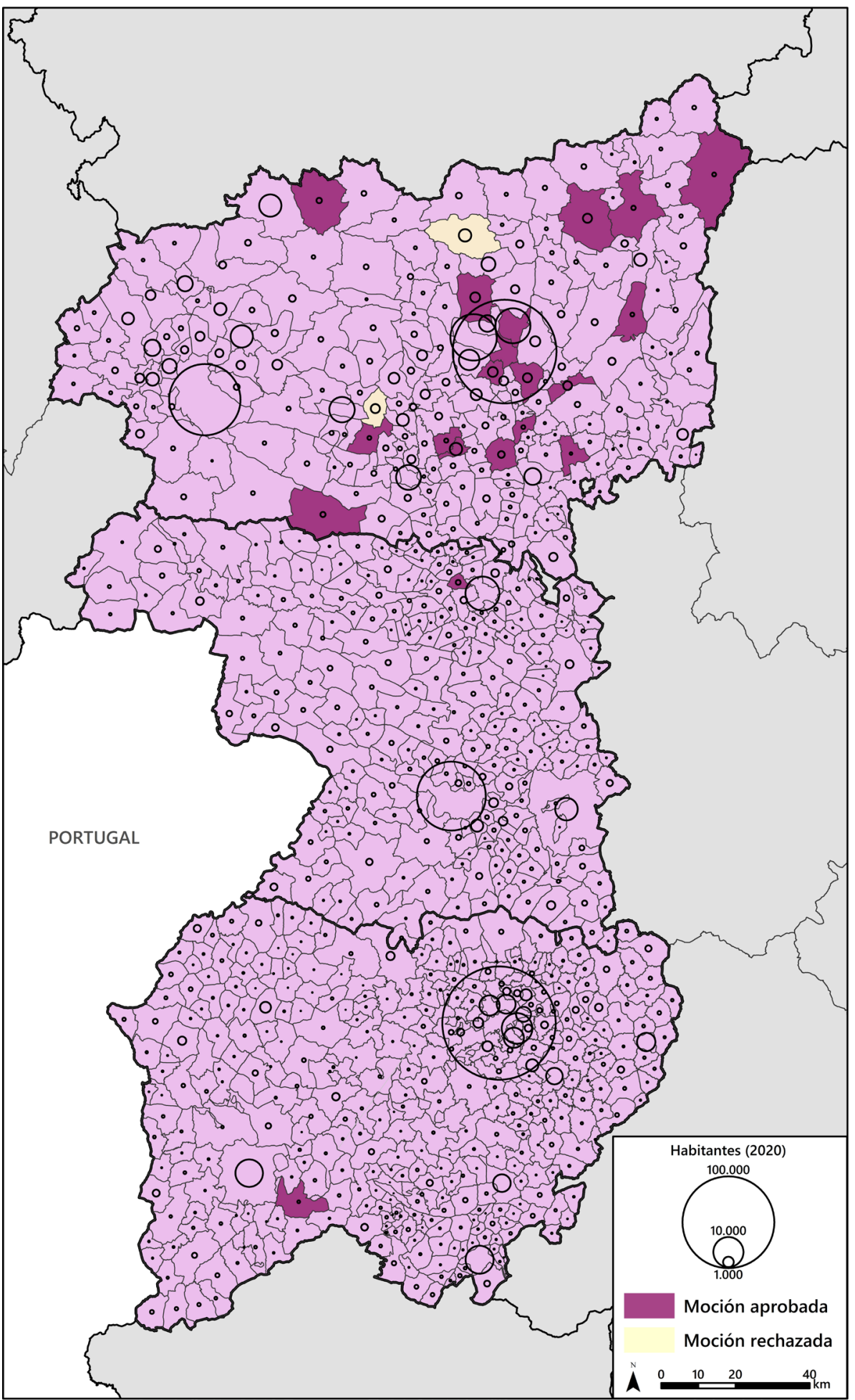

Figura 3. Ayuntamientos que han secundado y rechazado la moción (a 7/2/2020). Fuente: Elaboración propia. 
Con permiso, las entrevistas fueron grabadas para, posteriormente, transcribirlas y analizarlas con la ayuda del software NVivo 12. El apartado de resultados refleja la integración inclusiva (Valles 1999) de la información recogida en las entrevistas. Es decir, expone el análisis de su contenido, codificación y categorización. Se aportan unos fragmentos de texto considerados significativos, que van acompañados de un código numérico (desde E1 hasta E16) con el fin de salvaguardar la identidad de los interlocutores, cuestión fundamental en el necesario respeto por el carácter anónimo de las entrevistas de acuerdo con Taylor y Bogdan (1984), Valentine (2005), Seidaman (2006) o Kvale (2011), entre otros. En esa misma línea, para no marcar el género, cuando nos referimos a alguna de las personas entrevistadas se utiliza siempre el femenino.

\section{Resultados}

El análisis de las entrevistas realizadas conduce a varios núcleos de significado. De entrada, destaca el argumentario verbalizado a favor de las mociones pro-Lexit, en el que emerge con fuerza una percepción muy pesimista sobre el territorio y su actual inserción administrativa, marcada por la lógica del agravio. A continuación, se relata el testimonio sobre el desarrollo de las mociones desde una perspectiva de la política formal. Finalmente, el Lexit parece dibujarse como una realidad deseada, aunque de difícil consecución, y plantea un debate singular alrededor de su alcance geográfico.

\section{Las mociones como "grito de desesperación"}

Las mociones se conciben como el quejido de un territorio que está padeciendo un grave deterioro en las últimas décadas, y para el que urge una solución inmediata que impida su caída definitiva: «Creo que debemos de aprovechar la oportunidad porque entiendo que va a ser la última» (E16); «Es ese grito del que está desesperado y [lo] da [...] para que digan: “sé que no me voy a salvar, pero voy a dar el último chillido para que sepáis que estoy aquí"» (E9). Esta consternación se desagrega en dos planos. Por un lado, el diagnóstico sobre la situación crítica del territorio. Por el otro, un modelo político-territorial vigente percibido como desafortunado, que se concreta en varias realidades: centralismo, administración regional impuesta e intento de anihilar la identidad propia.

\section{«Cayó todo»}

Las entrevistadas describen la región como despoblada, envejecida y pasto de la emigración: «Nuestros hijos no es que no deseen vivir en León, es que no tienen más opción que irse de León» (E1). Dicha situación la correlacionan con una economía que juzgan en crisis. Aquí el argumento que cobra especial significación es la añoranza de un modelo industrial y minero que tuvo su apogeo hace décadas y que se ha esfumado, sin que hayan mediado alternativas. El sector primario también parece haber entrado en una dinámica recesiva 0 , al menos, se muestra incapaz de compensar la pérdida de empleo de la base económica tradicional: «León ha caído, ha caído porque básicamente la minería era la que la sostenía. [...] Cayó la minería, cayó la ganadería, cayó todo» (E16). Las entrevistadas mencionan que la administración podría haber buscado alternativas, por ejemplo, con el uso de fondos MINER provenientes 
de la Unión Europea, pero se cree que se desviaron a otros lugares y han carecido de impacto real en el lugar: "[La] Junta de Castilla y León [...] utiliza el dinero muchas veces de esos fondos MINER, [...] que se debían destinar a la creación de alternativas, a pagar las obligaciones que ellos tienen» (E6).

León es visto, en fin, como un espacio rural deprimido donde, además, se están recortando los servicios y faltan equipamientos e infraestructuras:

«Mi zona, hoy en día, es la típica zona rural en la que mayor parte de la gente que vive es de edad avanzada. [...] Las administraciones no hacen más que pegarnos hachazos para quitarnos los servicios básicos que es lo único que nos queda» (E9).

El diagnóstico resultante es muy pesimista, con una suerte de acumulación de catástrofes a las que intenta responder la iniciativa política que estudiamos: «León está tan mal, cada vez que sale una nota de prensa: en paro los campeones somos, en despoblación los grandes campeones, cuando aparece cualquier desgracia ahí está León en el primer nivel» (E5).

Este tipo de constataciones suelen ir acompañadas de una alusión al discurso de la «España vacía» o «vaciada», frecuentemente verbalizado como tal ${ }^{9}$. La pertenencia de León, y las otras «dos provincias leonesas», a esta realidad se justifica en base a lo antedicho. No obstante, encontramos una lectura crítica de esta postura:

«La "España vaciada" es [...] un término que a mí me parece poco afortunado. No me gusta lo de la "España vaciada" [...] porque parece que se ha vaciado intencionadamente. [...] El vaciamiento de los territorios rurales españoles es consecuencia del sistema en el que vivimos» (E11).

En todo caso, «España vacía» o «vaciada» en el contexto leonés parece adquirir un matiz claramente político al cuestionar la organización territorial vigente:

«En León lo estamos viendo, hay una crisis de la "España vaciada", pero aquí se está expresando también un cambio de marco territorial [...]. Parten de un mismo contexto de un abandono de esa España de interior, pero la reivindicación de Teruel es por el abandono, no cuestionan el marco administrativo que genera una identidad» (E14).

\section{«Del centralismo madrileño al vallisoletano»}

La inutilidad señalada de los fondos MINER administrados desde Valladolid es uno de los ejemplos de lo que se percibe como fiasco de la administración regional. Dentro de la actual Castilla y León, se establece siempre una comparación entre la suerte de Castilla, o una parte de ella, y la de León desde el establecimiento de la autonomía hace poco menos de cuatro décadas. Se acusa a la administración autonómica — la Junta de Castilla y León- de

9 El término se debe a Del Molino (2016). Desde su obra, se ha extendido el uso de «España vacía» —también «vaciada»- tanto mediática como políticamente. 
instigadora de un desequilibrio territorial, lo que implica la percepción de un territorio ganador versus León, perdedor:

«León es una provincia abandonada por el desarrollo de la comunidad autónoma en la que estamos donde solamente se cree en el eje Valladolid-Burgos y donde se está desarrollando toda la industria, [...] creando todo el empleo y la riqueza, [...] despreciando y humillando totalmente a la provincia de León» (E2).

En este sentido, el gobierno regional se considera distante e inhibidor del desarrollo territorial de León: «La Junta es una administración lejana y que siempre está intentando ponernos trabas y, además, sin ocultarse» (E3) (figura 4). Se suele concretar este rol nocivo para León en la ciudad de Valladolid, a la que se presenta como succionadora del territorio leonés: «No nos han llevado la catedral [de León] a Valladolid porque no han podido, pero no sé si con el tiempo piedra a piedra, grano a grano, irán llevándola, es una vergüenza» (E8). En este contexto, y si bien la descentralización de España se podría entender como el fin del centralismo madrileño, en León se percibe que Valladolid se ha erigido en nuevo baluarte capitalino; de esta forma, acaba por emerger un nuevo centralismo vallisoletano:

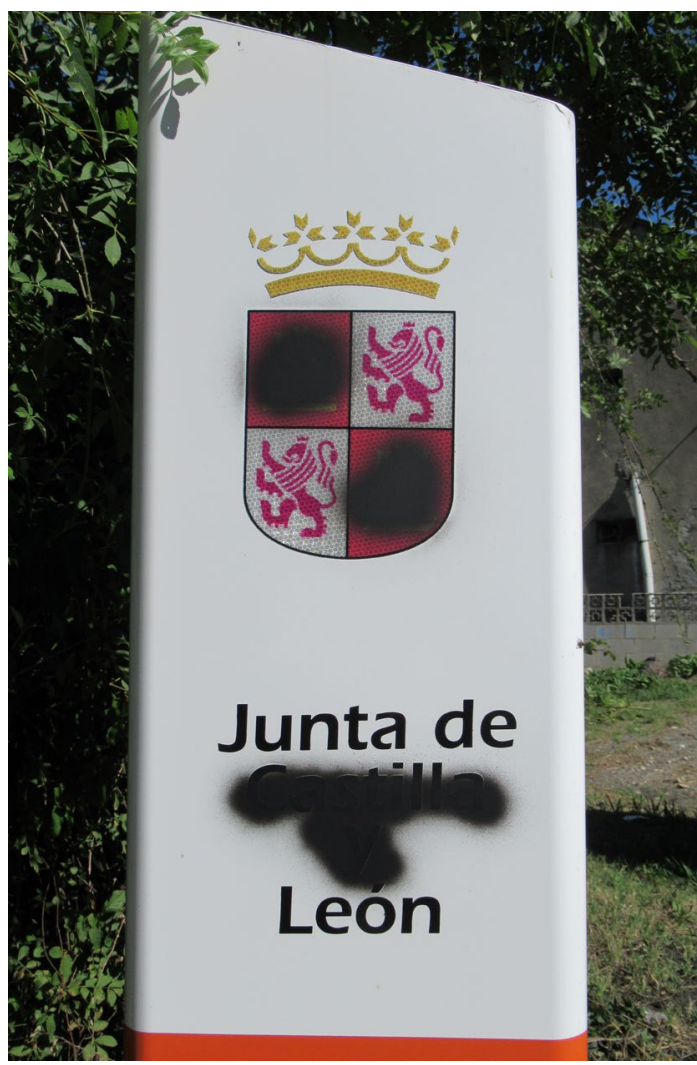

Figura 4. En los marcos miriamétricos de las carreteras de titularidad autonómica, en León se suele eliminar tanto el escudo como el corónimo castellanos, como en este caso en Santa Cruz del Sil (Páramo/Páramu del Sil).

Fuente: Fotografía propia (27/8/2020). 
«Yo lo que no quiero es saber nada de ese centralismo rancio que sustituyó a Madrid y que ahora es Valladolid. [...] Valladolid es una máquina de manipulación, se ha llevado todas las consejerías, todas las direcciones generales, el parlamento autonómico, [...] se lo han llevado todo, todo, pero todo» (E5).

\section{Castilla y León como «despropósito»}

La construcción en la década de 1980 de una comunidad autónoma con una capital de facto, que no de iure, en Valladolid es vista como como un «engendro» (E1) o un «despropósito» (E14) ajeno a los intereses y la voluntad de León. Se insiste en que Castilla y León es «totalmente artificial» (E1), resultante de la unión forzosa de dos realidades preexistentes que nada tienen que ver, pues «en ninguna otra comunidad se juntaron dos regiones o dos reinos para constituir una comunidad autónoma» (E1). En este sentido, se le concede gran valor explicativo a la presencia de la conjunción copulativa en el corónimo oficial: «León no es Castilla, y por eso se refleja la única comunidad autónoma de nombre compuesto que lleva la "y" en el medio, la única» (E7).

La actual comunidad autónoma es una realidad administrativa que genera frustración y desencanto entre nuestras entrevistadas. Se recuerda, en particular, que su creación se resolvió a espaldas del territorio, por intereses de alcance español: «Fue una decisión tomada más en despachos de Madrid que de la voluntad del pueblo, pero ni del pueblo leonés ni del pueblo castellano» (E14). En la visión de la ofensa, destacan las referencias a otras comunidades autónomas que se consideraban «castellanas» y a las que se les concedió autonomía (Cantabria y La Rioja), desgajadas de la que se presume era su matriz cultural e histórica; esto contrasta con un León que no es castellano y al que se le ha obligado a unirse a Castilla:

«El agravio es que todos lo tienen [el nivel de haber alcanzado una comunidad autónoma] menos nosotros, todos los que cumplían los rasgos constitucionales que marcaba la Constitución, y luego hay muchos que no los tienen y lo consiguen, en La Rioja o en Santander, más Castilla que es La Rioja o Santander no lo hay, ¡si Santander siempre fue el puerto de Castilla!» (E12).

«Ser de León» ante el «invento castellanoleonés»

En estas consideraciones subyace la asunción de una diferencia entre León y Castilla; en otras palabras, la consciencia de una idiosincrasia leonesa frente al resto del actual territorio autonómico en el que se encuentra hoy en día encasillado León, que se desgrana en distintas realidades, entre ellas la paisajística: «Yo no tengo nada que ver con una persona de Castilla, de Meseta. En mi pueblo hay vacas, hórreos, montañas, ríos y es todo verde, no es amarillo» (E15). Esta identidad leonesa parece tener que justificarse, de este modo, por oposición; en especial, respecto a una tendencia -otro agravio- que consiste en intentar generar una uniformidad castellanoleonesa inventada: «Que se respete algo tan simple como decir que solo somos leoneses, no somos castellanoleoneses, o inventos de ese estilo» (E14), pues «No hay nadie que sea leonés que te diga que su sentimiento es castellanoleonés» (E12). 
Las entrevistadas señalan en particular que desde la Junta de Castilla y León se están fomentando las actividades de la Fundación Villalar ${ }^{10}$, a la que acusan de «Gastar millón y pico de euros al año en crear identidad de Castilla y León» (E10). De esta forma, creen que se intenta promocionar una identidad inexistente - la castellanoleonesa- a pesar del rechazo generalizado y de no sentirla como algo propio. Al fin y al cabo, «Nosotros aquí siempre nos hemos sentido agraviados por las manipulaciones de la Junta de Castilla y León con nuestra historia y nuestra identidad» (E14).

Encontramos también algunos testimonios que se refieren a lo leonés sin necesidad de recurrir al contraste con Castilla: «Los leoneses somos leoneses porque tenemos una historia, una forma de ser, una identidad, una lengua, etc.» (E1). De todos modos, el tono del agravio resulta siempre inmanente, pues se considera que la identidad de la región ha sufrido una expoliación - se entiende que a manos de Castilla - y que, a pesar de todo, aún resiste: «Es una identidad histórica, cultural. Es viva porque hoy en día todavía está presente, todavía aún no han conseguido aniquilarnos como pueblo» (E14).

\section{El despliegue político-institucional de las mociones: «romper el techo de cristal» en un contexto protagonizado por el conflicto catalán}

A lo largo de las entrevistas se verbalizan referencias específicas al proceso catalán: «Yo sí veo que hay unas connotaciones muy próximas entre lo que se está viviendo entre el resto de España y Cataluña y el debate que genera toda esta resurrección del leonesismo» (E11). De todos modos, estas alusiones van siempre acompañadas de matices significativos efectuados por las entrevistadas para establecer diferencias entre ambos procesos. De entrada, se declara expresamente perseguir la conformación de una comunidad autónoma, sin poner en cuestión la integridad del Estado español: «León en ningún momento ha planteado nada parecido a la independencia, simplemente quiere crear una comunidad autónoma propia» (E13). Asimismo, se enfatiza que lo leonés no entra en contradicción con lo español: «Ser leonés es ser español, no es un procedimiento identitario contrapuesto» (E12). En último lugar, se subraya que una comunidad autónoma leonesa resulta «Una reivindicación justa, [...] constitucional, [...] cargada de argumentos» (E1), a diferencia del juicio que les merece una eventual independencia de Catalunya: «Quiero que León se independice, no como Cataluña, que no se confunda, León por derecho y por dignidad y porque nos han metido un gol» (E8).

Estas citas demuestran que se genera un paralelismo, incluso verbalizado, con el proceso catalán: el desafío al statu quo. Para que las mociones salgan adelante, están siendo necesarios apoyos más allá de los esperables del partido leonesista con más presencia institucional: la Unión del Pueblo Leonés -UPL-. Sin embargo, se nos comenta que los partidos de alcance español, el PP y PSOE principalmente, no desean que la iniciativa prospere, de modo que se les percibe contrarios a que «León despierte, que León tenga una

10 La Fundación Villalar-Castilla y León es una entidad — de carácter privado, aunque con capital públicocreada en 2003 y ligada a las Cortes autonómicas. Su finalidad principal es la divulgación y valorización de las señas de identidad de Castilla y León a través del desarrollo de diferentes actividades culturales. Desde febrero de 2020 suprime de su denominación el término «Villalar», que aludía al lugar en el que los comuneros castellanos batallaron en 1521 contra el ejército del emperador Carlos. 
fuerza reivindicativa ante Castilla» (E2). En este escenario, detectamos voces divergentes en ambos partidos mayoritarios en relación con las consignas que se reciben de sus sedes: «Yo la moción que presenté lo hice con todas las consecuencias, en contra de mi partido» (E8). Sin embargo, también se nos transmite un «miedo [...] a perder la silla» (E12), lo que lleva a determinados actores a posicionarse en contra de la autonomía.

Todo ello parece estar generando la sensación de transcender las lógicas del leonesismo político tradicional, protagonizado por la UPL, al alcanzar unos horizontes político-institucionales más amplios: «Aquí se ha abierto una puerta que muchos no creían que se pudiera abrir» (E13). En este sentido, ante una situación que se consideraba «adormilad[a]» (E11), se congratulan de que se «rompi[ese] el techo de cristal» (E14).

\section{Los futuros del Lexit: «LLa autonomía leonesa como solución posible?»}

La mayor parte de las entrevistadas coincide en que el recorrido del Lexit es arduo y su consecución, muy difícil. A pesar de ello, opinan que la situación no puede empeorar y se aferran a la esperanza de que el proceso iniciado actúe como un acicate que desencadene una reacción y rompa con el agonizante escenario en el que perciben hallarse: « $i$ Que la autonomía es la solución? A lo mejor no es la solución, pero peor no vamos a estar» (E12).

En este escenario, la sensación compartida es que una autonomía propia mejoraría la situación actual. Esta es presentada como una salida a los problemas que azotan este territorio. En ocasiones juzgamos una cierta idealización de la futura administración autonómica, la cual, se nos dice, contaría con muchos más recursos y una mayor capacidad de decisión. A su vez, se concibe una comunidad autónoma ligera, con poco peso administrativo, cercana y descentralizada, un modelo que se presenta antagónico al actual de Castilla y León: «Al ser más pequeña tú tienes más posibilidades y controlas lo que quieres para ti. [...] La autonomía lo que hace es financiarte, te regula, te fija unas infraestructuras, evita que desaparezcan los pueblos» (E4). Este planteamiento permitiría satisfacer la idiosincrasia de la región: «Lo importante es que nos autorregulamos, nos autorregimos, [...] que nosotros podemos ensalzar nuestro sistema organizativo, social, económico» (E5).

La mayor dificultad percibida para el avance del proceso de Lexit se encuentra en el sistema de partidos español. Los concejales en el territorio pueden desobedecer sus organizaciones, pero se reconoce que los aparatos políticos en Valladolid y Madrid difícilmente tolerarán cambiar el statu quo: «Esto es súper complicado, porque esto no depende de las personas, depende de los políticos, y está claro que los políticos no quieren» (E7). En este sentido, algunos testimonios, más que vislumbrar la obtención efectiva de la autonomía, consideran que el Lexit representa una llamada de atención: «Lo que ocurre es que tenemos que seguir manteniendo esa llama encendida» (E2). En todo caso, en las entrevistas subyace un espíritu positivo que puede ser capaz de sobrellevar las dificultades que se encuentren en el camino:

«El futuro lo veo de una forma optimista porque el presente es negativo, cualquier cambio es hacia mejor. [...] Soy optimista porque lo artificial nunca progresa, se mantiene, y lo natural sí que puede progresar. Esto poco a poco, sin ninguna prisa» (E5). 


\section{El alcance territorial de un hipotético León autónomo: entre una y tres provincias}

En la negociación sobre el futuro de León, encontramos una indefinición notable de la forma territorial de la Región Leonesa que se vindica. En este punto, los planteamientos son variopintos. Para algunas entrevistadas, la tensión entre una región con una sola provincia, con dos o con tres, resulta ociosa y defienden una opción voluntarista: «León es quien quiera ser León, pero lo de que tengas las tres provincias o una sola tampoco me lo planteo» (E12). Para otras, el realismo impone aceptar que la comunidad autónoma debe ser uniprovincial:

«Solo León. [...] Aquí en León hay un sentimiento leonés muy fuerte, y Salamanca y Zamora se ha ido perdiendo, un poco por el deterioro cultural, donde mejor se pueden conservar las señas de identidad leonesa es en León» (E14).

Esta visión se ampara en la lectura crítica de la conformación del mapa autonómico vigente: «Hay algunas cosas... Santander se sacó de Castilla la Vieja y está solo, La Rioja o Logroño, pues lo mismo... Murcia se dejó sola» (E10). En efecto, ¿si existen comunidades uniprovinciales, por qué León no lo puede ser? Finalmente, la tesis, de carácter más posibilista, consistente en la defensa de las tres provincias como futura comunidad autónoma parece admitir una cierta gradualidad:

«Es León, Zamora y Salamanca, evidentemente tenemos que ir paso a paso, estamos trabajando mucho lo que es la provincia de León. Nosotros creemos que, cuando caiga León, va a caer Zamora y Salamanca. [...] Nuestro ideario es irrenunciable. Son las tres, pero puede ir por fases» (E15).

\section{Discusión y conclusiones}

Este trabajo pretende interpretar el proceso del Lexit acaecido en el tránsito entre 2019 y 2020 bajo la óptica de la NGR, de manera que nos permita reflexionar con un caso empírico acerca de la bondad del enfoque teórico y, en clave más específica, sobre la posibilidad de que se consolide una nueva región por la vía política, es decir, que en España pueda constituirse una nueva comunidad autónoma. Aceptamos con ello el reto apuntado por Paasi et al. (2018) de entender las regiones y el regionalismo en su contexto. A su vez, se procuran comprender las causas del Lexit y de su difusión, así como plantearse las opciones de continuidad en el tiempo de esta iniciativa.

Podría parecer que el Lexit - en tanto proceso como denominación singular- ha surgido de repente, casi de una manera inesperada. Cabría, por lo tanto, plantearse en primer lugar los condicionantes que han facilitado la conformación de un nuevo «imaginario subestatal», en los términos acuñados por Agnew (2018). Para ello, resulta pertinente acudir al concepto de «ventana de oportunidad» señalado en el modelo teórico de conformación regional de Lagendijk (2007). A tenor de los resultados obtenidos, identificamos tres de ellas:

- Una constante sensación de agravio respecto a otros territorios, tanto de España —el relato de la «España vacía/vaciada»— como de la propia Castilla 
y León, lo que viene acompañado de una crítica al centralismo, sea el estatal de Madrid o el ejercido por Valladolid en el marco de la comunidad autónoma; en este agravio, tampoco se pueden menospreciar las referencias a La Rioja o a Cantabria, que se consideran según el relato recabado «castellanas» pero a las que se les ha permitido desgajarse de su matriz, mientras que en el caso leonés se ha obligado a una unión forzosa.

- La reivindicación secesionista de Catalunya iniciada en 2010 ha abierto el debate sobre la organización territorial del Estado; de este modo, se posibilita criticar el modelo territorial y, con ello, la propia conformación de las comunidades autónomas.

- En una escala superior, el proceso del Brexit ha supuesto romper con una Unión Europea de los 28 que se creía intocable; se ha demostrado con ello que las piezas del puzle territorial son cambiables.

Los dos discursos últimos no han estado presentes hasta época reciente, por lo que no se podían invocar en el pasado; y, sin duda, el planteamiento de la «España vacía» es posterior a Del Molino (2016). En definitiva, esta oleada de 2019-2020 se distingue de las anteriores (García Álvarez 2002; Ferrer 2017) porque aprovecha nuevas «ventanas de oportunidad», en los términos de Lagendijk (2007).

Podría afirmarse que, en el debate de los imaginarios, los actores del Lexit están poniendo sobre la mesa un discurso propio. De las tres opciones que distingue Keating (2017) a la hora de explorar las opciones de construir una región, los elementos socioeconómicos destacan sobre los gubernamentales o identitarios. Esto es, las recurrentes quejas referidas a empleo, infraestructuras o salud parecen ser las razones fuertes para que ciertos actores promuevan las mociones, más allá de la búsqueda de una forma de gobierno autónoma o de reivindicar una identidad propia. De esta manera, se concuerda con los enfoques «estratégico-relaciones» (MacLeod 2001; Jessop et al. 2008), que apuntan a la necesidad de estudiar las condiciones sociales, económicas y políticas en la que se mueven los actores para el estudio regional; en esta misma línea, debe interpretarse que la identidad estratégica y funcional cobra en este caso más fuerza que la cultural (Houtum y Lagendijk 2001). En este punto, el análisis realizado permite plantear una crítica al modelo de Paasi (1986), escorado hacia cuestiones culturales, narrativas e identitarias, que en nuestro caso no alcanzan demasiada potencia, lo que no obsta para que se pueda hablar de un proceso de construcción regional. Esta inferencia corrobora las conclusiones de Paül y Haslam Mckenzie (2015) para Australia Occidental. En definitiva, inferimos que el modelo de Lagendijk (2007) resulta más pertinente. En términos de MacLeod (2001), cabe no perder de vista los elementos «duros» (sociales, económicos, etc.) en la NGR, pues la interpretación de Paasi (1986) parece apoyarse en los «blandos».

De hecho, el modelo de Paasi (1986, 1991 y 2001) empieza con el establecimiento de la forma territorial para la región; esto es, en último término, se requeriría de un mapa, un logotipo en expresión de Anderson (1986), que ayude a identificar la región. Sin embargo, en el caso estudiado se produce una ambigüedad territorial relevante: desde la defensa de un 
Lexit solo con la provincia de León, a imagen y semejanza de otras comunidades autónomas uniprovinciales, a la reivindicación triprovincial, incluso con un matiz de gradualidad (primero, León; después, se unirán las otras, o tal vez una de ellas). Cabe no perder de vista que esta variabilidad territorial viene de lejos — con una pulsión, ya presente en la edad moderna, sobre qué provincias son leonesas-. En esta línea, García Álvarez (2002) ya había circunscrito la reivindicación de un León autónomo a la provincia homónima desde el inicio del régimen de 1978.

Burgueño (2011) advierte que la identidad provincial en buena parte de la antigua Corona de Castilla está muy arraigada; por ello, la articulación de regiones pluriprovinciales resulta siempre problemática, tal y como García Álvarez (2002) relata detalladamente. Al fin y al cabo, no se puede olvidar que, para $\operatorname{Agnew}(2018,24)$, la principal dificultad que plantea el hecho regional, que considera «lábil y resbaladizo», estriba en la fijación de sus fronteras. Es más, desde una perspectiva ontológica, buena parte de la NGR surge como reacción a una visión asentada de la región como realidad indudable dotada de fronteras definidas y atemporales (cfr. Lacoste 1976; García Álvarez 2006). El caso aquí estudiado contribuye a desmentir este planteamiento ya desfasado. A su vez, cabe tener en cuenta que el corónimo no parece despertar en nuestras entrevistadas demasiado acuerdo - ¿Región Leonesa, Comunidad Autónoma Leonesa, León, País Leonés, (Antiguo) Reino de León...? (figura 5)—, lo que revela la existencia de diversas visiones sobre el nombre - y los límites asociadosde la nueva entidad regional; esto es muestra de la dificultad de encontrar un término único para la región, atribución que estaría conectada con la segunda fase del modelo de Paasi (1986).

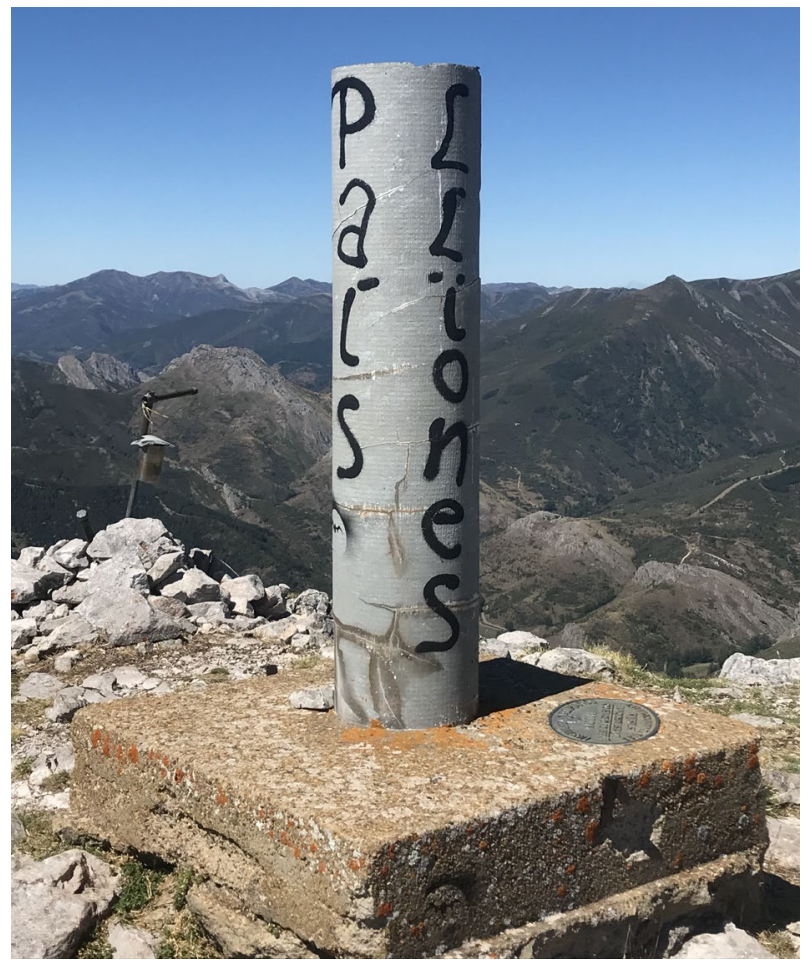

Figura 5. Las pintadas reivindicativas suelen hacer referencia a "País Llïonés», como esta del Pico Bodón (Valdelugueros/Valdellugueros).

Fuente: Fotografía propia (25/8/2020) 
Sea como fuere, estamos ante la conformación de un imaginario regional leonés que, por el momento, no parece ser el hegemónico, en el sentido dado por Lagendijk (2007). Es relevante entonces preguntarse por su duración en el tiempo, tal y como nos plantean Paasi et al. (2018). Mientras las mociones continúan sucediéndose (figuras 2 y 6), el proceso sigue vigente y el debate está sobre la mesa. Podríamos defender que el Lexit es la cresta de la ola de un renacimiento del leonesismo, tal y como apunta Ferrer (2017). No obstante, puede que una debilidad estructural en el corto plazo, señalada por Salgado (2016), provoque que la fuerza de esta reivindicación territorial se pierda. En todo caso, nos parece que la crisis territorial abierta en España a partir del irresuelto conflicto catalán (Gómez Mendoza et al. 2013; Farinós et al. 2019; Rullan y Vives 2020) deja el futuro más abierto que en otros contextos. En la década de 1980, por ejemplo, tal y como se ha explicado en los antecedentes y relatan de manera evidente las entrevistadas - señal de que resultó ser un episodio traumático, o, al menos, que se ha transmitido como tal desde entonces-, algunas comunidades autónomas como Castilla y León pudieron conformarse «desde arriba». Sin embargo, parece dudoso que en el escenario actual pueda suceder algo semejante.

En España se ha tendido a dar por cerrado el modelo autonómico instituido rápidamente después de la Constitución de 1978. Esta investigación ha puesto de manifiesto la idoneidad de interpretar lo que sucede en el contexto español en relación con marcos analíticos globales, como el ofrecido por Agnew (2018). En este sentido, Agnew $(2018,28)$ ha señalado que se sigue produciendo un aumento a favor de la institución política de regiones, sobre todo en ámbitos juzgados como «periféricos», para de este modo procurar una capacidad de decisión propia en el terreno político y económico. Interpretamos el Lexit desde esta perspectiva, en tanto que una manifestación local - para nada inocente, sino altamente significativa- de una tendencia general, que encuentra además unos ingredientes específicos que pueden ser movilizados con facilidad: leonesismo, reivindicación de una historia, identidad paisajística, etc. En definitiva, los elementos necesarios para la emergencia de León en tanto que región están presentes; no obstante, el modelo de conformación regional más conocido de la NGR, el de Paasi (1986), nos recuerda que deben ser (re)configurados para que se pueda iniciar una verdadera construcción regional. Pensamos que el Lexit apunta a ese momento de salida; no nos queda, por ahora, más que esperar para ver cómo puede evolucionar este proceso.

\section{Epílogo}

Desde el 27 de diciembre de 2019 hasta el 31 de marzo de 2021, 58 ayuntamientos de las tres provincias leonesas han presentado la moción de autonomía (figura 6). La votación ha sido favorable casi en su totalidad, en 50 de los 58 . Con todo, resulta destacable que 48 de los 50 ayuntamientos que han secundado la moción pertenecen a la provincia de León. En términos de población, suponen el 49\% de los habitantes de la provincia homónima (unos 222.706 habitantes - INE, 2020-). De hecho, la moción fue aprobada en varios de los municipios más populosos de la provincia como San Andrés del Rabanedo (30.549 hab.), Villaquilambre (18.684 hab.) o Valverde de la Virgen (7.377 hab.), además del municipio capitalino (124.028 hab.). Cabe señalar también que uno de los municipios que ha apoyado 
la moción es berciano: Torre del Bierzo. La iniciativa, en la mayor parte de los casos, ha sido presentada por la UPL, aunque la geometría de apoyos en los distintos plenos ha sido variopinta. Así, concejales de partidos políticos que a escala nacional se han manifestado claramente contrarios a la iniciativa aquí estudiada, como el PP, Ciudadanos o Vox, han acabado apoyando o se han abstenido en sus respectivos plenos.

La conformación de una nueva comunidad autónoma, tanto uniprovincial como integrada por varias provincias, es una cuestión que no concita consenso puesto que los preceptos de la actual Constitución de 1978 que tratan esta cuestión son objeto de distintas interpretaciones. De hecho, para Clavero Arévalo (1983) o García de Enterría (2008), el Título VIII, relativo a las comunidades autónomas, resulta ser el tema «más delicado» de la Carta Magna.

Para los partidarios de una nueva comunidad autónoma, entre los que se encuentran los principales dirigentes de la UPL, la actual Constitución ofrece este camino. En este sentido, se apoyan, en primer término, en el art. 2 de la Constitución, en tanto que «reconoce y garantiza el derecho a la autonomía de las nacionalidades y regiones», pues entienden que la Región Leonesa es una de dichas regiones. Este supuesto se vería reforzado por el art. 143, al afirmar que «las provincias limítrofes con características históricas, culturales y económicas comunes, y las provincias con entidad regional histórica podrán acceder a su autogobierno y constituirse en comunidades autónomas». Este artículo explicita que la iniciativa autonómica corresponde a la diputación, o diputaciones provinciales, así como a las dos terceras partes de los municipios afectados y siempre que su población represente la mitad del censo electoral. En la actualidad, se está lejos de estos parámetros ya que solo 48 de los 211 municipios de la provincia de León (el 23\%) han respaldado la moción (figura 6). Para estos mismos políticos a favor del proceso autonómico, esta vía constitucional no sería necesaria si se optase por seguir el art. 144, que determina que las Cortes Generales podrían crear una nueva comunidad autónoma sin contar con las corporaciones locales y únicamente apoyándose en «motivos de interés nacional».

Sin embargo, son varios los expertos en Derecho Constitucional como Garrido (2002) o López Aguilar (2012), para los que la creación de una nueva comunidad autónoma requeriría previamente de una reforma de la Constitución. Así, consideran que el art. 2, más que apoyar la creación de nuevas autonomías, lo que viene es a garantizar las existentes. Y respecto de los art. 143 y 144 consideran que no tendrían validez en el momento presente, ya que su finalidad era fijar la organización territorial de un proceso cerrado y consolidado, sin que quepa volverlos a invocar. Este parecer se basa en la Sentencia 89/1984 del Tribunal Constitucional, que puso fin a la reivindicación de «León solo», tal y como se ha constatado más arriba: «Los actos a que se refiere el artículo 143 son, como el propio precepto indica, actos de iniciativa, actos de primera impulsión del proceso que agotan sus efectos cuando éste [sic] ha entrado en su siguiente fase». ${ }^{11}$ Otra fórmula invocada sería la modificación del Estatuto de Autonomía de Castilla y León, redefiniendo el ámbito territorial de la comunidad autónoma. Esta reforma debería ser aprobada por las Cortes autonómicas y por las Cortes 
Generales. En cualquier caso, parece clara la dificultad de encontrar una fórmula jurídica de posible institución de la comunidad autónoma leonesa.

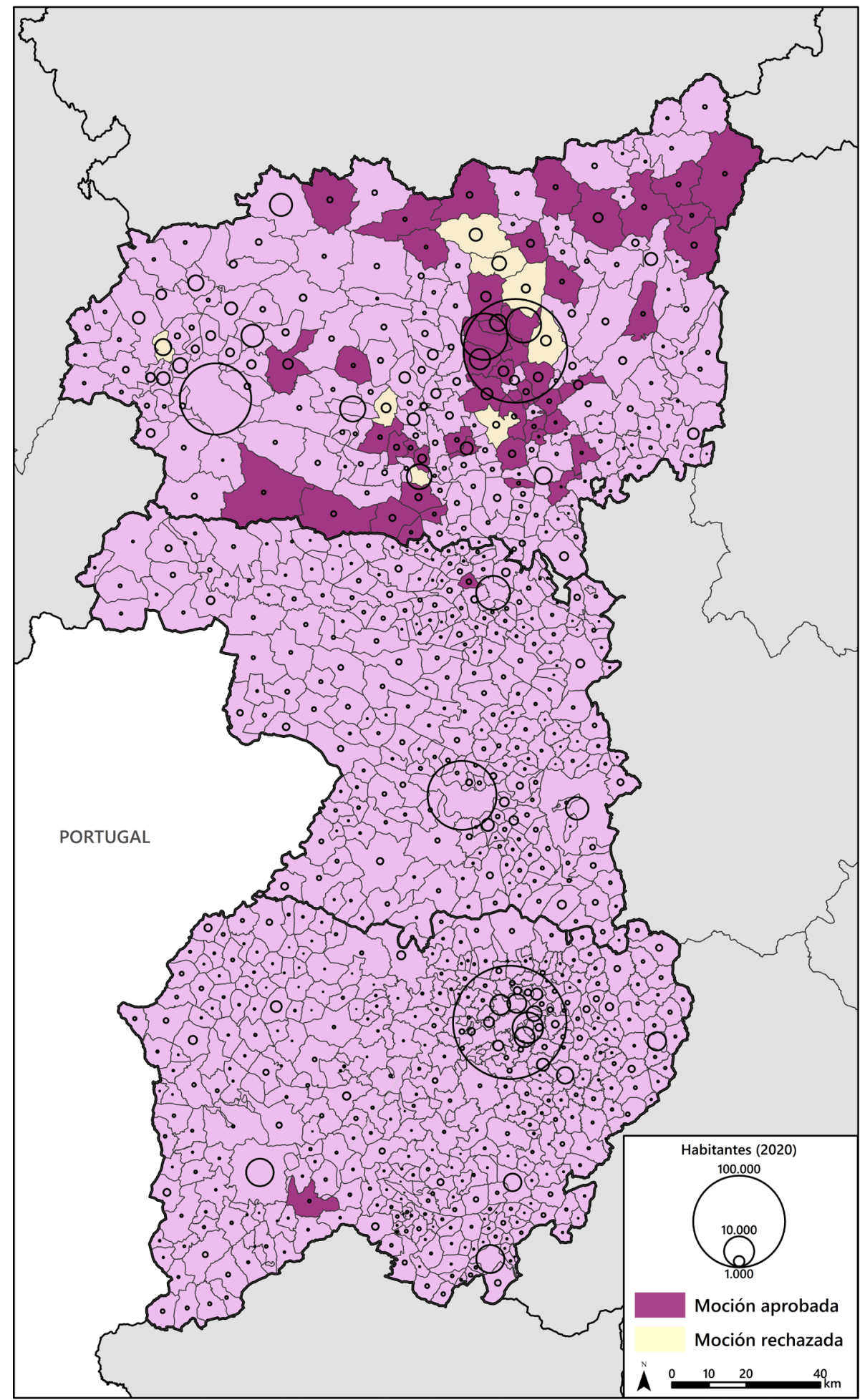

Figura 6. Ayuntamientos que han secundado y rechazado la moción (a 31/3/2021). Fuente: Elaboración propia. 


\section{Bibliografía}

Agnew, John. 2018. "Evolution of the Regional Concept". En Geographies of Regions and Territories, editado por Anssi Paasi, John Harrison y Martin Jones, 1-20. Cheltenham/ Northampton: Edward Elgar Publishing.

Anderson, Benedict. 1986. Imagined Communities: Reflections on the Origins and Spread of Nationalism. London: Verso.

Andrade, Xosé Miguel; López Carreira, Anselmo. 2020. O Reino medieval de Galicia. Crónica dunha desmemoria. Vigo: Xerais.

Burgueño, Jesús 1996. Geografía política de la España constitucional. La división provincial. Madrid: Centro de Estudios Políticos y Constitucionales.

Burgueño, Jesús. 2011. La invención de las provincias. Madrid: Catarata.

Cameron, Jenny. 2016. "Focusing on the Focus Group”. En Qualitative Research Methods in Human Geography, editado por Iain Hay, 203-224. Melbourne: Oxford University Press.

Clavero Arévalo, Manuel. 1983. España, desde el centralismo a las autonomías. Madrid: Planeta.

Cochrane, Allan. 2018. "Relational Thinking and the Region”. En Geographies of Regions and Territories, editado por Anssi Paasi, John Harrison y Martin Jones, 79-88. Cheltenham/ Northampton: Edward Elgar Publishing.

De Hoz, Javier. 2010. "Las lenguas del Noroeste peninsular y las relaciones entre astures y galaicos". Larouco, 5: 17-38.

Del Molino, Sergio. 2016. La España vacía: viaje por un país que nunca fue. Madrid: Turner.

Farinós, Joaquín; Fernández Enríquez, Alfredo. 2017. "Hacia una renovada visión de la región en geografía”. En Geografía Regional de España: espacios y sociedades, editada por Joaquín Farinós y Jorge Olcina, 19-78. València: Tirant lo Blanch.

Farinós, Joaquín; Ojeda, Juan F.; Trillo, Juan Manuel. ed. 2019. España: Geografías para un Estado posmoderno. Madrid/Barcelona: AGE/Geocrítica.

Fernández Rei, Francisco. 2007. "Plurilingüismo y contacto de lenguas en la Romania europea”. En Manual de lingüística románica, coordinada por José Enrique Gargallo y María Reina Bastardas, 477-516. Barcelona: Ariel.

Ferrer, Rodrigo. 2017. La construcción de un pueblo. El regionalismo leonés. San Andrés de Rabanedo: Cultural Norte.

García Álvarez, Jacobo. 2002. Provincias, regiones y comunidades autónomas: la formación del mapa político de España. Madrid: Senado.

García Álvarez, Jacobo. 2006. “Geografía regional”. En Tratado de Geografía Humana, dirigida por Daniel Hiernaux y Alicia Lindón, 25-70. Rubí/México: Anthropos.

García de Enterría, Eduardo. 2008. "El sistema descentralizador de las comunidades autónomas tras la Constitución de 1978”. Revista de Administración Pública, 175, 217 250.

Garrido, Vicente. 2002. "La Constitución y la estructura territorial del Estado: a propósito de la reforma del Senado y de la división provincial". Cuadernos Constitucionales de la Cátedra Fadrique Furió Ceriol, 40, 69-74. 
Gómez Mendoza, Josefina; Lois, Rubén Camilo; Nel·lo, Oriol. 2013. Repensar el Estado. Santiago de Compostela: Universidade de Santiago de Compostela.

Houtum, Henk van; Lagendijk, Arnoud. 2001. "Contextualising Regional Identity and Imagination in the Construction of Polycentric Urban Regions: The Cases of the Ruhr Area and the Basque Country". Urban Studies, 38 (4): 747-767. Doi: 10.1080/00420980120035321.

Instituto Nacional de Estadística. [En línea]. Cifras oficiales de población de los municipios españoles: Revisión del Padrón Municipal. https://www.ine.es/. [Consulta 1/3/2021].

Jessop, Bob. 2001. "Institutional Re(turns) and the Strategic-Relational Approach". Environment and Planning A, 33 (7): 1213-1235. Doi: 10.1068/a32183.

Jessop, Bob; Brenner, Neil; Jones, Martin. 2008. "Theorizing Socio-Spatial Relations". Environment and Planning D: Society and Space, 26 (3): 389-401. Doi: 10.1068/d9107.

Jones, Martin; Paasi, Anssi. 2015. Regional Worlds: Advancing the Geography of Regions. London: Routledge.

Keating, Michael. 2017. “Contesting European Regions”. Regional Studies, 51 (1): 9-18. Doi: 10.1080/00343404.2016.1227777.

Kvale, Steinar. 2011. Las entrevistas en investigación cualitativa. Madrid: Ediciones Morata. Lacoste, Yves. 1976. La géographie, ça sert, d'abord, à faire la guerre. Paris: La Découverte.

Lagendijk, Arnoud. 2007. "The Accident of the Region: A Strategic Relational Perspective on the Construction of the Region's Significance". Regional Studies, 41 (9): 1193-1208. Doi: 10.1080/00343400701675579.

López Aguilar, Juan Fernando. 2012. “De la Constitución 'irreformable' a la reforma constitucional 'exprés'”. Teoría y Realidad Constitucional, 29, 199-218.

López Carreira, Anselmo. 2005. O reino medieval de Galicia. Contribución á súa historia política. Vigo: A Nosa Terra.

Lune, Howard; Berg, Bruce L. 2017. Qualitative Research Methods for the Social Sciences. Harlow: Pearson.

MacLeod, Gordon. 1998. "In What Sense a Region? Place Hybridity, Symbolic Shape, and Institutional Formation in (Post-)Modern Scotland". Political Geography, 17 (7): 833863. Doi: 10.1016/S0962-6298(98)00041-9.

MacLeod, Gordon. 2001. "Beyond Soft Institutionalism: Accumulation, Regulation, and Their Geographical Fixes". Environment and Planning A, 33 (7): 1145-1167. Doi: $10.1068 / a 32194$.

Madoz, Pascual. 1846-1850. Diccionario geográfico-estadístico-histórico de España y sus posesiones de ultramar. Madrid: Establecimiento tipográfico de P. Madoz y L. Sagasti.

Maxwell, Joseph A. 2013. Qualitative Research Design: An Interactive Approach. Thousand Oaks: SAGE.

Nogueira, Camilo. 2001. A memoria da nación. O reino de Gallaecia. Vigo: Xerais.

Paasi, Anssi. 1986. "The Institutionalization of Regions: A Theoretical Framework for Understanding the Emergence of Regions and the Constitution of Regional Identity". Fennia, 164 (1): 105-146. Doi: 10.11143/9052. 
Paasi, Anssi. 1991. "Deconstructing Regions: Notes on the Scales of Human Life”. Environment and Planning A, 23 (2): 239-256. Doi: 10.1068/a230239.

Paasi, Anssi. 1996. Territories, Boundaries, and Consciousness: The Changing Geographies of the Finnish-Russian Border. Chichester: John Wiley.

Paasi, Anssi. 2001. "Europe as a Social Process and Discourse: Considerations of Place, Boundaries and Identity". European Urban and Regional Studies, 8 (1): 7-28. Doi: 10.1177/096977640100800102.

Paasi, Anssi. 2004. "Place and Region: Looking Through the Prism of Scale". Progress in Human Geography, 28 (4): 536-546. Doi: 10.1191/0309132504ph502pr.

Paasi, Anssi; Harrison, John; Jones, Martin. 2018. "New Consolidated Regional Geographies". En Geographies of Regions and Territories, editada por Anssi Paasi, John Harrison y Martin Jones, 1-20. Cheltenham/Northampton: Edward Elgar Publishing.

Paasi, Anssi; Metzger, Jonathan. 2017. "Foregrounding the Region”. Regional Studies, 51 (1): 19-30. Doi: 10.1080/00343404.2016.1239818.

Paül, Valerià; Haslam McKenzie, Fiona. 2015. '“About Time the Regions Were Recognised': Interpreting Region-Building in Western Australia". Australian Geographer, 46 (3): 363-388. Doi: 10.1080/00049182.2015.1049242.

Rodríguez González, M. $\underline{\text { a }}$ Carmen; Durany, Mercedes. 1997. “Galicia desde 0 Bierzo. Proxección e diferencias na ocupación e organización do territorio". En O feito diferencial galego. Galicia fai dous mil anos. A Historia, coordinada por Gerardo Pereira Menaut, I, 413-444. Santiago de Compostela: A Editorial da Historia/Museo do Pobo Galego.

Ruiz Olabuénaga, José Ignacio. 1999. Metodología de la investigación cualitativa. Bilbo: Universidad de Deusto.

Rullan, Onofre; Vives, Sònia. 2020. "El conflicto Cataluña/España: una revisión desde la Geografía”. Boletín de la Asociación de Geógrafos Españoles, 84: 1-37. Doi: 10.21138/bage.2755.

Salgado, Carlos Javier. 2016. La evolución de la identidad regional en los territorios del antiguo Reino de León (Salamanca, Zamora, León). Salamanca: Universidad de Salamanca.

Santos, Juan. 2010. "Etnias indígenas y administración romana en la franja de contacto asturgalaica miradas desde la perspectiva astur". Larouco, 5: 51-59.

Seidman, Irving. 2006. Interviewing as Qualitative Research: A Guide for Researchers in Education and the Social Sciences. New York: Teachers College, Columbia University.

Sum, Ngai-Ling. 2004. “From 'Integral State' to 'Integral World Economic Order': Towards a Neo-Gramscian Cultural International Political Economy". Cultural Political Economy Working Paper Series, 7.

Taylor, Steven J.; Bogdan, Robert. 1984. Introduction to Qualitative Research Methods. The Search for Meanings. New York: John Wiley \& Sons.

Trillo, Juan Manuel. 2014. "Cross-Border Regions: The Gap Between the Elite's Projects and People's Awareness. Reflections from the Galicia-North Portugal Eurorregion". Journal of Borderlands Studies, 29 (2): 257-273. 
Doi: 10.1080/08865655.2014.915704.

Valentine, Gill. 2005. “Tell Me About'...: Using Interviews as a Research Methodology”. En Methods in Human Geography, editada por Robin Flowerdew y David Martin, 110-127. Harlow: Pearson.

Valles, Miguel S. 1999. Técnicas cualitativas de investigación social. Madrid: Síntesis.

(C) Copyright Valerià Paül, Roberto Vila-Lage, Alejandro Otero y Juan Manuel Trillo, 2021 (C) Copyright: Scripta Nova, 2021.

Ficha bibliográfica:

PAÜL, Valerià; VILA-LAGE, Roberto; OTERO, Alejandro y TRILLO, Juan Manuel. ¿Hacia una comunidad autónoma leonesa? Una interpretación urgente del Lexit de inicios de 2020 desde la perspectiva de la Nueva Geografía Regional. Scripta Nova. Revista Electrónica de Geografía y Ciencias Sociales. Barcelona: Universitat de Barcelona, vol. 25, Núm. 3(2021), p. 165-193. ISSN: 1138-9788]

DOI: $10.1344 / \operatorname{sn} 2021.25 .32289$ 